This is the peer-reviewed version of the following article:

Prado, V., Lence, E., Vallejo, J., Beceiro, A., Thompson, P., Hawkins, A., \& González-Bello, C. (2016). Study of the Phosphoryl-Transfer Mechanism of Shikimate Kinase by NMR Spectroscopy. Chemistry - A European Journal, 22(8), 2758-2768, which has been published in final form at https://doi.org/10.1002/chem.201504438. This article may be used for non-commercial purposes in accordance with Wiley-VCH Terms and Conditions for Self-Archiving 


\title{
Study of the Phosphoryl-Transfer Mechanism of Shikimate Kinase by NMR Spectroscopy
}

\author{
Verónica Prado, ${ }^{[a]}$ Emilio Lence, ${ }^{[a]}$ Juan A. Vallejo, ${ }^{[b]}$ Alejandro Beceiro, ${ }^{[b]}$ Paul Thompson, ${ }^{[c]}$ Alastair R. \\ Hawkins $^{[\mathrm{c}]}$ and Concepción González-Bello*[a]
}

\begin{abstract}
The phosphoryl-transfer mechanism of shikimate kinase from Mycobacterium tuberculosis and Helicobacter pylori, an attractive target for antibiotic drug discovery, has been studied by $1 \mathrm{D}$ ${ }^{1} \mathrm{H}$ and ${ }^{31} \mathrm{P}$ NMR spectroscopy. Metaphosphoric acid proved to be a good mimetic of the metaphosphate intermediate in the ready and rapid evaluation by NMR of a dissociative mechanism. The required closed form of the active site for catalysis was achieved by the use of ADP (product) or two synthetic ADP analogues (AMPNP, AMPCP). The Molecular Dynamics simulation studies reported here also revealed that the essential arginine (Arg116/Arg117 in H. pylori and $M$. tuberculosis, respectively), which activates the $y$-phosphate group of ATP for catalysis and triggers the release of the product for turnover, would also be involved in the stabilization of the metaphosphate intermediate during catalysis. We believe that the studies reported here would be helpful for the future structure-based design of inhibitors of this attractive target. The reported approach would also be useful to study the possible dissociative mechanism of other kinase enzymes.
\end{abstract}

\section{Introduction}

Phosphoryl-transfer reactions are amongst the most fundamental processes in biological systems. These reactions are crucial in the biosynthesis and replication of nucleic acids, the synthesis and assembly of key metabolites in a large variety of metabolic pathways and in energy and signal transduction, amongst others [1-7]. This type of reaction can proceed by three mechanistically different nucleophilic substitution pathways: (A) dissociative, in which a trigonal metaphosphate intermediate is

[a] V. Prado, Dr. E. Lence, Prof. C. González-Bello Centro Singular de Investigación en Química Biolóxica e Materiais Moleculares (CIQUS),

Universidade de Santiago de Compostela calle Jenaro de la Fuente $\mathrm{s} / \mathrm{n}$,

15782 Santiago de Compostela, Spain

E-mail: concepción.gonzalez.bello@usc.es

[b] Dr. J. A. Vallejo, Dr. A. Beceiro

Servicio de Microbioloxía-INIBIC,

Complexo Hospitalario Universitario A Coruña (CHUAC),

Hospital Teresa Herrera,

As Xubias, 84,

15006 A Coruña, Spain

[c] Dr. P. Thompson, Prof. A. R. Hawkins

Institute of Cell and Molecular Biosciences, Medical School,

University of Newcastle upon Tyne,

Catherine Cookson Building, Framlington Place,

Newcastle upon Tyne NE2 4HH, UK

Supporting information for this article is given via a link at the end of the document. formed first by cleavage of the O-P bond in the donor, followed by subsequent nucleophilic attack of the acceptor; (B) associative, in which the nucleophile adds to the donor first with the formation of a pentavalent phosphorane intermediate, and then the leaving group is released; and $(C)$ concerted, which proceeds through a single transition state with simultaneous cleavage and formation of two single bonds through a pentavalent transition state as in $S_{N} 2$ reactions (Scheme 1) [4,5] These pathways differ in the timing of the cleavage of the phosphorus-leaving group bond and the formation of the phosphorus-nucleophile bond. The concerted process is a onestep process with no intermediate. In contrast, associative and dissociative mechanisms are two-step processes that do involve an intermediate, although there are quite different (trigonal or trigonal bipyramid, respectively). Moreover, in the dissociative process, the acceptor is not involved in the intermediate. Examples of the three possible mechanisms have been described, although the reasons for the selection of a particular pathway for a given kinase are still unclear [8-13].

Considering that many drugs that are highly successful in human clinical use mimic a transition state of a recognized target enzyme, a detailed knowledge of the catalytic mechanism of a chosen enzyme can be valuable for the rational design of mimetics (inhibitors) that can be used as drugs. Examples of drugs that are transition-state analogues include oseltamivir, a neuraminidase inhibitor in the treatment of the influenza virus, and saquinavir, an HIV protease inhibitor used in the treatment of AIDS. Structural studies have contributed greatly to this issue with the resolution of crystal structures of diverse kinases in complex with transition state analogues, reaction intermediates or metal fluoride complexes (e.g., $\mathrm{AlF}_{3}$ and $\mathrm{BeF}_{3}{ }^{-}$) [8-11,14-15]. However, these techniques require large quantities of protein, they are time-consuming and, in many cases, it is difficult to find crystallization conditions to obtain crystals that provide good diffraction data. Phosphoryl-transfer reactions have also been studied by hybrid QM/MM calculations and this approach allows the study of bond making and breaking in a dynamic context that allows the reorganization of active site residues, substrate, and water molecules during the whole reaction coordinate [16-18]. However, due to the very demanding computational cost, the application of QM is still limited to a relatively small number of atoms, which is an issue for large active sites - particularly when the highest levels of theory are employed. We report here NMR studies that allowed the ready and rapid determination of the phosphoryl-transfer mechanism of a recognized attractive target for antibiotic drug discovery, namely shikimate kinase [19]. 
A) Dissociative

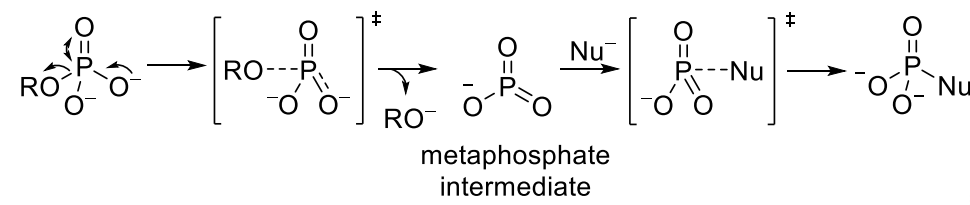

B) Associative (addition - elimination)

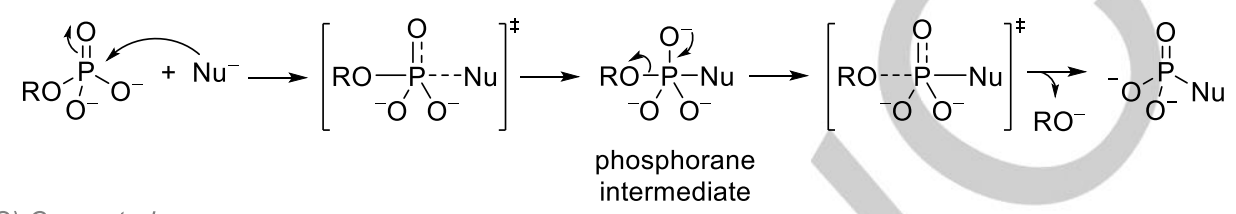

C) Concerted

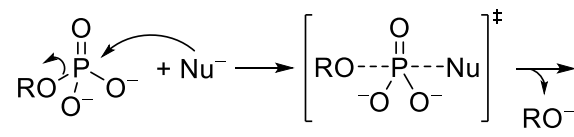

Scheme 1. Phosphoryl-transfer reaction mechanisms.

Shikimate kinase (SK, EC 2.7.1.71, aroK gene), the fifth enzyme of the shikimic acid pathway, catalyses the stereospecific phosphorylation of the C3 hydroxyl group of shikimic acid (1) by transferring the $\mathrm{y}$-phosphate group of ATP to the hydroxyl group to provide shikimate 3-phosphate (2) and ADP (Figure 1). SK is essential in several relevant pathogenic bacteria such as Mycobacterium tuberculosis, which is responsible for tuberculosis, Helicobacter pylori, which is the causative agent of gastric and duodenal ulcers and has also been classified as a type I carcinogen, and Pseudomonas aeruginosa, which is one of the most common pathogens in healthcare-associated infections and represents $13 \%$ of multidrug-resistant strains to nearly all antibiotics. SK has three domains (Figure 1): (1) the CORE domain that contains five stranded parallel $\beta$-sheets and the P-loop, which forms the binding site for ATP and ADP; (2) the LID domain, which has an essential arginine for the binding of ATP (Arg116/Arg117 in H. pylori and M. tuberculosis, respectively); and (3) the substrate binding (SB) domain, which is responsible for the recognition and binding of shikimic acid (1). Structural and Molecular Dynamics (MD) simulation studies revealed that SK is exquisitely designed to recognize the unfavourable conformation of shikimic acid (1), which has a diaxial disposition of the C4 and C5 hydroxyl groups [20-22]. In this arrangement, the enzyme enables a selective phosphorylation of the C3 hydroxyl group in 1, which is arranged in an equatorial disposition. MD simulation studies also revealed that there are three key structural factors for catalysis: (1) a closed form of the LID domain to allow activation of the $y$ phosphate of ATP by the guanidinium group of the essential arginine (Arg116/Arg117 in H. pylori and M. tuberculosis, respectively); (2) a closed form of the SB domain in order to bring the substrates together for the phosphoryl-transfer reaction and to isolate the substrate within an apolar cavity, which is controlled mainly by two phenylalanine residues; and (3) a flexible LID and SB domain for product release, which is triggered by the essential arginine [14].<smiles>O=C([O-])C1=C[C@@H](O)[C@H](O)[C@H](O)C1</smiles>



Figure 1. Enzymatic conversion of shikimic acid (1) to shikimate-3-phosphate (2) catalyzed by SK and its Michaelis complex. The three domains of $H$. pylori SK enzyme are shown: CORE (purple), LID (red) and SB (yellow). 
Given the important features of the SK enzyme, we recently became interested in the possible development of new antimicrobials that function by inhibition of this enzyme. To this end, the knowledge of the catalytic mechanism of this enzyme will be helpful for the mechanism- and structure-based design of inhibitors. We report here NMR studies that allowed the determination of the phosphoryl-transfer mechanism of the SK enzyme. Molecular Dynamics (MD) simulation studies with the $M$. tuberculosis and $H$. pylori SK enzymes were also carried out to gain a better understanding of the dynamic behaviour of the enzyme Michaelis complex and the stability of the proposed metaphosphate intermediate. We believe that the approach described here would also be useful for the evaluation of possible dissociative phosphoryl-transfer mechanisms of other kinase enzymes.

\section{Results and Discussion}

Based on the results of structural studies, it was suggested that Asp33/Asp34 (in H. pylori and M. tuberculosis, respectively) would act as a general base to deprotonate the C3 hydroxyl group in 1 for nucleophilic attack [21]. More importantly, it was proposed the phosphoryl-transfer reaction catalysed by SK proceeds through an associative mechanism with consequent generation of a pentacovalent phosphorane intermediate (Scheme 1B) [21]. As a consequence, both substrates would be involved in the reaction intermediate. However, MD simulation studies carried out with the SK Michaelis complex (SK/ATP/1) from Mycobacterium tuberculosis (Mt-SK) and Helicobacter pylori ( $\mathrm{Hp}$-SK) showed that in both cases the distance between the $\mathrm{y}$-phosphate of ATP and the oxygen atom of the C3 hydroxyl group of $\mathbf{1}$ is over $5 \AA$ during most of the simulation (Figure 2 and $\mathrm{S} 1$ ). It is important to highlight that single $\mathrm{O}-\mathrm{P}$ bonds are typically $\sim 1.6 \AA$.

These Michaelis complexes were prepared using the enzyme geometries found in the crystal structures of Mt-SK (PDB code 2IYQ [21]) and Hp-SK (PDB code 3MUF [20]) in complex with ADP and shikimic acid (1) or shikimate-3-phosphate (2), respectively, after manual replacement of the corresponding enzyme products by their substrates. The monomer of each SK in aqueous solution obtained using the molecular mechanics force field AMBER was employed [23]. These MD simulation studies revealed that both substrates seem to be quite far away for an associative or concerted mechanism, in which both donor and acceptor would be linked via a phosphorus atom, and the dissociative mechanism appears to be plausible. If the conversion of shikimic acid (1) into shikimate 3-phosphate (2) would take place by a dissociative mechanism, a metaphosphate intermediate that would be recognized by the enzyme would be generated and no covalent linkage between ATP and 1 would be required. In an effort to evaluate this hypothesis, we explored the possible conversion of 1 into 2 catalysed by $\mathrm{Hp}$-SK and Mt-SK in the absence of ATP and by external addition of metaphosphoric acid as a mimetic of the metaphosphate intermediate. The possible formation of $\mathbf{2}$ was followed by $1 \mathrm{D}{ }^{1} \mathrm{H}$ and ${ }^{31} \mathrm{P}$ NMR spectroscopy.

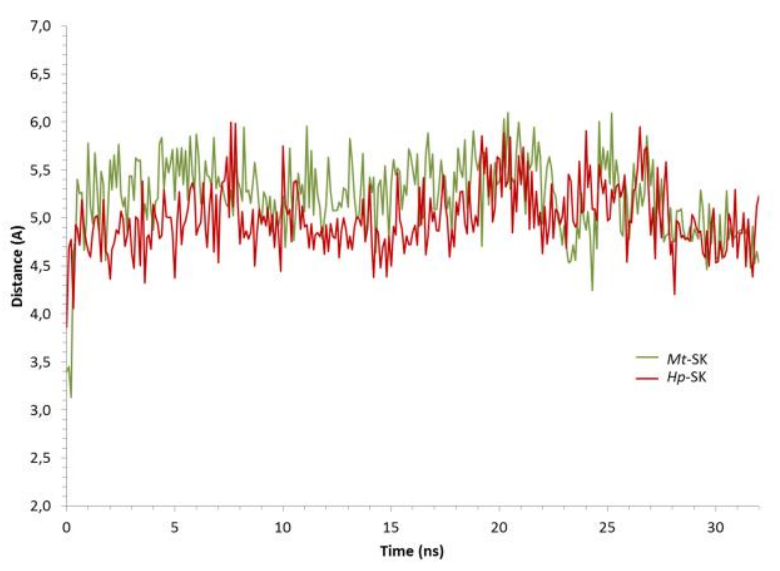

Figure 2. Relative distance between substrates in Michaelis complexes. Variation of the distance between the phosphorus atom of ATP $\gamma$-phosphate and the $\mathrm{C} 3$ oxygen atom of 1 during 32 ns of MD simulation of the $M$. tuberculosis (green) and H. pylori (red) SK/ATP/1 Michaelis complexes.

The $H$. pylori enzyme used in these studies was expressed and produced using genomic DNA from an isolated clinical strain, courtesy of Guadalajara Hospital (Guadalajara, Spain). Mt-SK was produced and purified as described previously [24]. ADP was used in these experiments on considering previously reported circular dichroism [25], fluorescence [26] and structural $[20,24]$ studies, which suggested that the ATP binding induces a large movement of the LID domain over the active site to bring two key arginines into close contact with the ATP and that a closed active site is required for catalysis [22]. Specifically, this process involved the conserved residues Arg107/Arg110 and the essential residues Arg116/Arg117 in $H$. pylori and $M$. tuberculosis, respectively. In this arrangement, the appropriate disposition of ATP in the active site, which is controlled by a cation- $\pi$ interaction with Arg107/Arg110, and the activation of the $\mathrm{Y}$-phosphate of ATP by the guanidinium group of the essential arginine would occur. As shown in Figure 3, comparison of the crystal structures of $M t-S K / A D P / 1$ (PDB 2IYQ, [21]) and $M t-S K / 1$ (2IYS, [21]) complexes shows that in the absence of ADP the LID is in the open conformation and the essential Arg117 is located over $20 \AA$ away from the active site. The Mt-SK/ADP/1 crystal structure (PDB 2IYQ) also revealed that a closed conformation of the active site is achieved in the presence of ADP. More importantly, superposition of the $M t-S K$ Michaelis complex and the Mt-SK/ADP/1 crystal structure highlights how the essential Arg117 is pointing towards the active site. Therefore, we consider that by using ADP (product) in the NMR experiments a similar conformation of the active site for catalysis would also be generated.

The $1 \mathrm{D}^{1} \mathrm{H}$ and ${ }^{31} \mathrm{P}$ NMR monitoring of the formation of shikimate 3-phosphate (2) from shikimic acid (1) catalysed by $\mathrm{Hp}$-SK in the presence of ADP after the addition of metaphosphoric acid, a polymeric form of $\mathrm{HOPO}_{2}$, is shown in Figure 4. The natural enzymatic conversion of shikimic acid (1) and ATP catalysed by Mt-SK to give shikimate 3-phosphate (2) and ADP was also studied by NMR spectroscopy (Figure S2). The latter 
experiments were carried out using very small amounts of Mt-SK, which also has a high $K_{\mathrm{m}}$, in order to follow easily the enzymatic conversion. As it is shown in Figure S2, conversion of ATP into ADP was not observed in the absence of $\mathbf{1}$ but it is a very fast process after the addition of $\mathbf{1}$. Control experiments showed that the reaction did not occur in the absence of ADP (Figure S3) or in the absence of enzyme (Figure S4). In addition, the use of other commercially available mimetics of the metaphosphate intermediate such as barium or aluminium metaphosphate failed due to their lack of solubility under the reaction conditions.

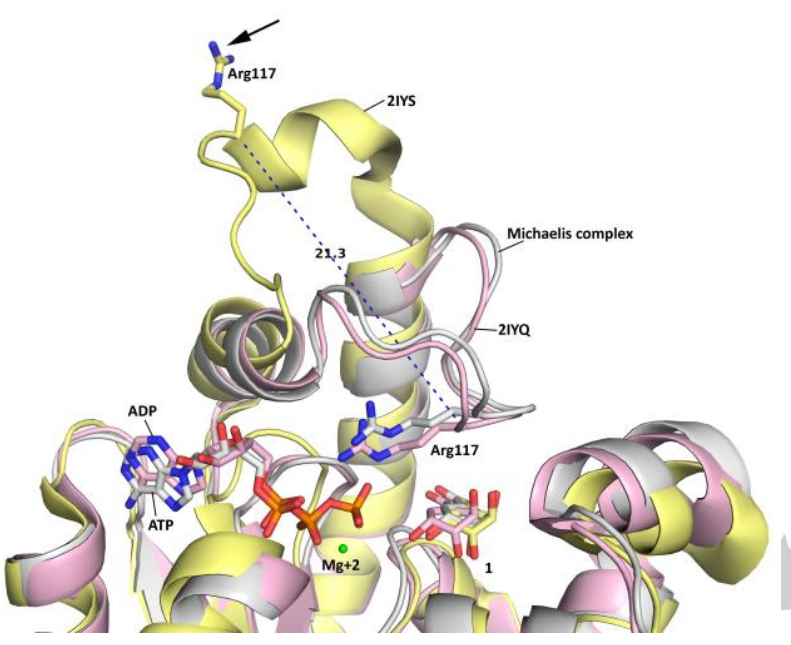

Figure 3. Superposition of the crystal structures of $M t-S K / A D P / 1$ (PDB 2IYQ,[20]) and Mt-SK/1 (2IYS, [20]) complexes and Mt-SK Michaelis complex. Note how in the absence of ADP or ATP the LID is in the open conformation and the essential Arg117 is located over $20 \AA$ away from the active site.

1D ${ }^{1} \mathrm{H}$ and ${ }^{31} \mathrm{P}$ NMR spectra of a mixture of $\mathbf{1}$ and ADP in the presence of a catalytic amount of the Hp-SK enzyme were recorded before (Figure 4A) and after the addition of metaphosphoric acid (Figures 4B-E). After 10 minutes of incubation (Figure 3B), the formation of 2 could already be detected and it was clearly observed after 6 hours (Figure 4C). The most relevant signals in the $1 \mathrm{D}^{1} \mathrm{H}$ and ${ }^{31} \mathrm{P}$ NMR spectra that reveal the formation of 2 are: (a) one singlet $\left(\delta_{H} 6.39 \mathrm{ppm}\right)$ and two multiplets $\left(\delta_{H} 3.98 \mathrm{ppm}\right.$ and $\left.3.76 \mathrm{ppm}\right)$ in the ${ }^{1} \mathrm{H}$ NMR spectra corresponding to $\mathrm{H} 2, \mathrm{H} 5$ and $\mathrm{H} 4$ of 2, respectively; (b) one singlet $\left(\delta_{P} 0.6 \mathrm{ppm}\right)$ in the ${ }^{31} \mathrm{P} N \mathrm{NMR}$ spectra corresponding to the phosphate group of 2 . Similar results were obtained on using the Mt-SK enzyme (Figure S5). We assume that the singlet observed in the ${ }^{31} \mathrm{P}$ NMR spectra at $\delta_{\mathrm{P}}-0.1 \mathrm{ppm}$ (Figure 4B) after the addition of metaphosphoric acid corresponds to some hydrolysis of this acid (phosphoric acid) and that it is also observed in the control experiments carried out in the absence of enzyme or ADP (Figures S4 and S3, respectively). However, control experiments on the stability of metaphosphoric acid showed that this compound is quite stable under the assay conditions as significant changes were not observed in the ${ }^{31} \mathrm{P}$ NMR monitoring and it can therefore be used for the reported NMR studies (Figure S6).
Comparison of the experiments carried out in the presence of ADP and with the external addition of metaphosphoric acid (Figure 3) with the ${ }^{1} \mathrm{H}$ and ${ }^{31} \mathrm{P}$ NMR monitoring of the natural formation of shikimate 3-phosphate (2) from shikimic acid (1) and ATP catalysed by Mt-SK (Figure S2) revealed that the stereospecific phosphorylation of the C3 hydroxyl group of 1 takes place in the reported experiments as in the natural enzymatic conversion. The findings that: (1) no reaction is observed in the absence of enzyme, (2) a closed conformation of the active site is required for reaction, i.e. with the essential arginine in close contact with the substrates/products, which is achieved by using ADP and (3) nonspecific phosphorylation reactions of the other hydroxyl groups were detected, all suggest that the enzyme seems to be able to recognize metaphosphoric acid, more likely the terminal part of this polymer, in a similar way to the reaction intermediate to subsequently undergo a nucleophilic attack by the C3 hydroxyl group in 1. These results also revealed that no covalent linkage between donor and acceptor seems to be required for enzymatic catalysis since shikimic acid (1) can be converted into shikimate 3-phosphate (2) by external addition of a mimetic of the metaphosphate intermediate (second step of dissociative process).

In order to prove that the presence of ADP is required to achieve the appropriate arrangement for catalysis but that it does not participate in the reaction, two synthetic analogues of ADP, namely AMPNP and AMPCP, were also employed (Figures 5 and 6). Adenosine-5'-[( $\alpha, \beta)$-imido]diphosphate (AMPNP) and adenosine-5'-[( $\alpha, \beta)$-methyleno]diphosphate (AMPCP), are ADP analogues in which the $\beta$-phosphate is replaced by a imidophosphate and a methylenophosphate derivatives, respectively. As it is shown in Figure 5, the NMR results indicate that $\mathrm{Hp}$-SK also catalyses the stereospecific phosphorylation of the C3 hydroxyl group of $\mathbf{1}$ by addition of metaphosphoric acid in the presence of AMPNP. The latter experiments also highlight the required closed form of the LID for catalysis. Remarkably, this process was much faster than when using ADP. Thus, to achieve $\sim 50 \%$ conversion, incubation for 24 hours is required when using ADP vs only 2 hours for AMPNP. In contrast, the experiments carried out using AMPCP showed that the conversion of $\mathbf{1}$ into $\mathbf{2}$ is much slower (Figure 6). In fact, the enzymatic reaction required the use of much large quantities of metaphosphoric acid and under these conditions only 20\% conversion was obtained.

Considering that the differences observed on using ADP, AMPNP and AMPCP would be due to some differences in achieving a closed arrangement of the active site, MD simulation studies were performed. These studies were also carried out in aqueous solution using the molecular mechanics force field AMBER. The three possible $\mathrm{Hp}$-SK/L/1 complexes were then subjected to $50 \mathrm{~ns}$ of dynamic simulation ( $\mathrm{L}=\mathrm{AMPNP}, \mathrm{AMPCP}$ or ADP). As it is shown in Figure 7, AMPNP proved to be the ligand that provides the most efficient closed form of the active site with the essential arginine side chain in close contact with the phosphate groups of the ligand and with the shikimic acid (1) anchored in the SB domain in the appropriate conformation for reaction [22]. Significant changes were not observed during the whole simulation and a tidy closed active site seems to be 
achieved (Figure 7A). A similar situation was obtained with the $H p-S K / A D P / 1$ complex. In contrast, for the Hp-SK/AMPCP/1 complex, a less stable closed arrangement of the active site was obtained (Figure 7B).

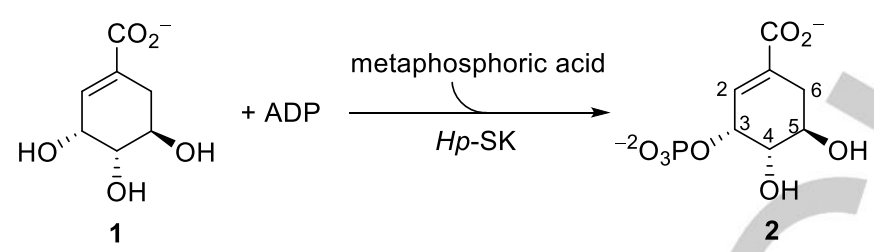

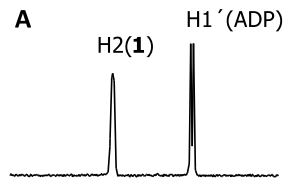

B

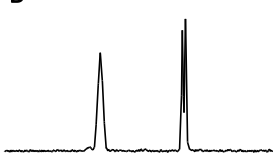

C

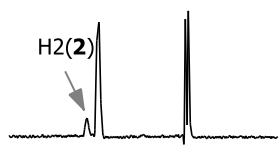

D

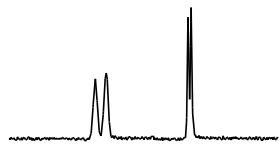

E

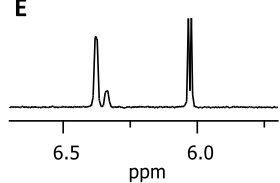



H5(1)


H6ax(2)


Figure 4. $1 \mathrm{D}{ }^{1} \mathrm{H}$ and ${ }^{31} \mathrm{P}$ NMR monitoring of the enzymatic conversion of shikimic acid (1) to shikimate 3-phosphate (2) catalysed by $\mathrm{Hp}$-SK in the presence of ADP and metaphosphoric acid. ${ }^{1} \mathrm{H}$ and ${ }^{31} \mathrm{P}$ NMR spectra: (A) of 1, ADP and $\mathrm{Hp}$-SK under the assay conditions. (B) 10 min after the addition of metaphosphoric acid $(18 \mathrm{mM})$ to $(\mathrm{A})$. (C) after $6 \mathrm{~h}$ incubation. (D) after $24 \mathrm{~h}$ incubation. (E) after $96 \mathrm{~h}$ incubation. All experiments were recorded at $500 \mathrm{MHz}\left({ }^{1} \mathrm{H}\right)$ or $202 \mathrm{MHz}\left({ }^{31} \mathrm{P}\right)$ and $298 \mathrm{~K}$ using ADP $(4.5 \mathrm{mM}), 1(6.4 \mathrm{mM})$ and a catalytic amount of $\mathrm{Hp}$-SK (10 units) in Tris- $d_{11} . \mathrm{DCl}(100 \mathrm{mM}, \mathrm{pD} 7.7), \mathrm{KCl}(100 \mathrm{mM})$ and $\mathrm{MgCl} 2(5 \mathrm{mM})$. Only relevant regions of the ${ }^{1} \mathrm{H}$ NMR spectra are shown for clarity. The most relevant signals that reveal the formation of 2 are marked with an arrow (C). The observed ${ }^{31} \mathrm{P}$ signals in the ADP solution, which corresponds to phosphate $(\mathrm{Pi}), \beta$-phosphate of ADP $(\mathrm{Pb})$ and $\alpha$-phosphate of ADP $(\mathrm{Pa})$, are labeled.

Our simulation studies inidicate that significant motion in the substrate covering-loop, the essential arginine and SB domain would occur. As a consequence, the substrate seems to be less anchored in the SB domain for the enzymatic reaction to occur. The binding free energy of shikimic acid (1) in the three $\mathrm{Hp}$ SK/L/1 complexes was calculated using the MM/PBSA [27] approach in explicit water (GB) as implemented in AMBER. The results suggest that $\mathbf{1}$ has about a 6 -fold higher affinity for the $\mathrm{Hp}$-SK/ADP and Hp-SK/AMPNP complexes than for the HpSK/AMPCP one. We consider that this motion might be responsible for the experimentally observed lower efficiency of the enzymatic conversion when AMPCP is used. 


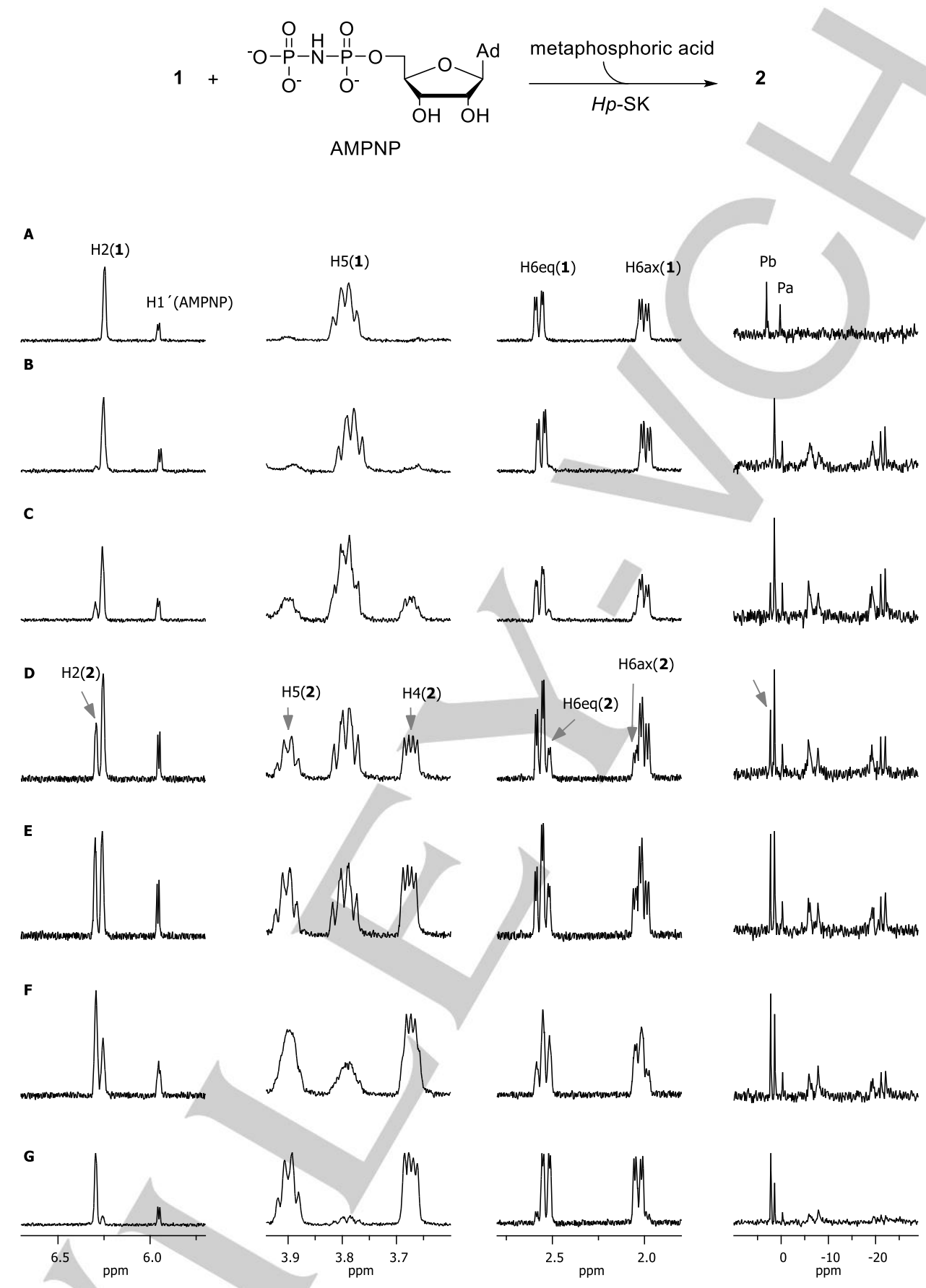

Figure 5. 1D ${ }^{1} \mathrm{H}$ and ${ }^{31} \mathrm{P}$ NMR monitoring of the enzymatic conversion of shikimic acid (1) to shikimate 3-phosphate (2) catalysed by $\mathrm{Hp}$-SK in the presence of AMPNP and metaphosphoric acid. ${ }^{1} \mathrm{H}$ and ${ }^{31} \mathrm{P}$ NMR spectra: (A) 1, AMPNP and Hp-SK under the assay conditions. (B) after addition to (A) of metaphosphoric acid $(18 \mathrm{mM})$. (C) after $20 \mathrm{~min}$ incubation. (D) after $1 \mathrm{~h}$ incubation. (E) after $2 \mathrm{~h}$ incubation. $(\mathrm{F})$ after $5 \mathrm{~h}$ incubation. (G) after $24 \mathrm{~h}$ incubation. All experiments were recorded at $500 \mathrm{MHz}\left({ }^{1} \mathrm{H}\right)$ or $202 \mathrm{MHz}\left({ }^{31} \mathrm{P}\right)$ and $298 \mathrm{~K}$ using shikimic acid $(3.2 \mathrm{mM})$, AMPNP $(1.8 \mathrm{mM})$ and a catalytic amount of $\mathrm{Hp}$-SK (10 units) in Tris- $d_{11}$.DCl $(100 \mathrm{mM} \mathrm{pD} 7.7), \mathrm{KCl}(100 \mathrm{mM})$ and $\mathrm{MgCl}_{2}(5 \mathrm{mM})$. Only relevant regions of the ${ }^{1} \mathrm{H}$ NMR spectra are shown for clarity. The most relevant signals that reveal the formation of 2 are marked with an arrow (D). The ${ }^{31} \mathrm{P}$ and ${ }^{1} \mathrm{H}$ signals shown in panel A corresponding to relevant peaks of $\mathbf{1}$ and $\mathrm{AMPNP}$ are labelled. Pb, Pa and Pi correspond to $\beta$ - and $\alpha$-phosphate of AMPNP and phosphate, respectively. Ad = adenosine moiety. 



$\mathrm{H} 2(\mathbf{1})$
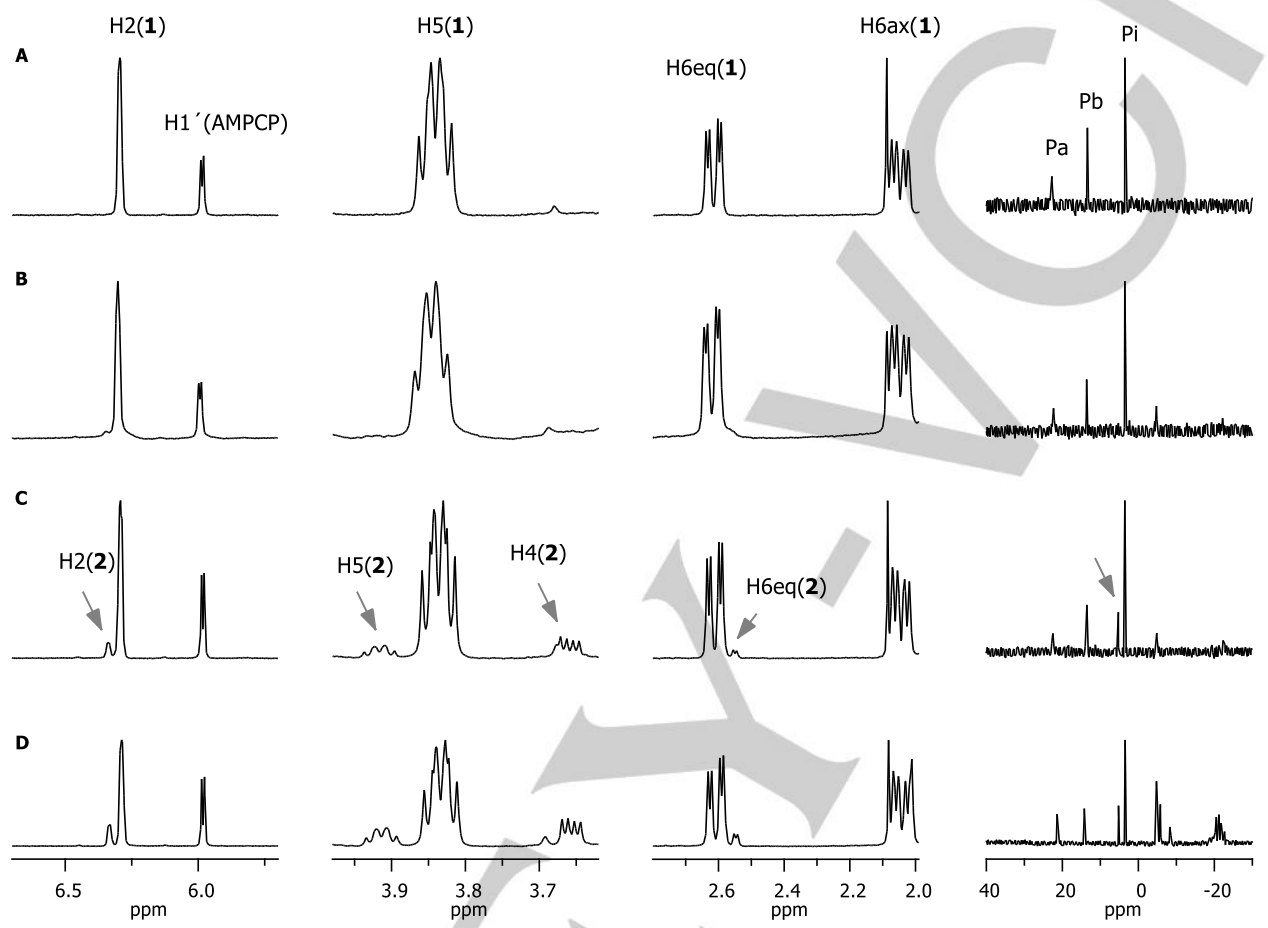

Figure 6. $1 \mathrm{D}{ }^{1} \mathrm{H}$ and ${ }^{31} \mathrm{P}$ NMR monitoring of the enzymatic conversion of shikimic acid (1) to shikimate 3-phosphate (2) catalysed by $\mathrm{Hp}$-SK in the presence of AMPCP and metaphosphoric acid. ${ }^{1} \mathrm{H}$ and ${ }^{31} \mathrm{P}$ NMR spectra: (A) 1, AMPCP and Hp-SK under the assay conditions. (B) after addition to (A) of metaphosphoric acid (36 mM). (C) after $18 \mathrm{~h}$ incubation. (D) after addition to (C) of metaphosphoric acid (total concentration $54 \mathrm{mM}$ ) and $33 \mathrm{~h}$ incubation. All experiments were recorded at $500 \mathrm{MHz}\left({ }^{1} \mathrm{H}\right)$ or $202 \mathrm{MHz}\left({ }^{31} \mathrm{P}\right)$ and $298 \mathrm{~K}$ using shikimic acid $(3.2 \mathrm{mM})$, AMPCP $(4.5 \mathrm{mM})$ and a catalytic amount of $\mathrm{Hp}$-SK $\left(10\right.$ units) in Tris- $d_{11}$. DCl $(100 \mathrm{mM} \mathrm{pD} 7.7), \mathrm{KCl}(100 \mathrm{mM})$ and $\mathrm{MgCl}_{2}(5 \mathrm{mM})$. Only relevant regions of the ${ }^{1} \mathrm{H}$ NMR spectra are shown for clarity. The most relevant signals that reveal the formation of 2 are marked with an arrow $(\mathrm{C})$. The ${ }^{31} \mathrm{P}$ and ${ }^{1} \mathrm{H}$ signals shown in panel A corresponding to relevant peaks of 1 and $\mathrm{AMPCP}$ are labelled. Pb, Pa and $\mathrm{Pi}$ correspond to $\beta$ - and $\alpha$-phosphate of AMPCP and phosphate, respectively. Ad = adenosine moiety.

In an effort to gain an insight into the stability and the binding mode of the proposed metaphosphate intermediate in the active site of $\mathrm{Hp}$-SK, MD simulation studies were performed. The Hp$\mathrm{SK} / \mathrm{ADP} / \mathrm{PO}_{3} / \mathbf{1}$ complex was then subjected to $50 \mathrm{~ns}$ of dynamic simulation. As shown in Figure 8, the metaphosphate intermediate remains trapped between the ADP and the shikimic acid (1) during the simulation, mainly due to the strong electrostatic interactions with the guanidinium group of the essential Arg116, the side chain of Lys14 and $\mathrm{Mg}^{2+}$. This process can be clearly visualized by analyzing the variation of the distances involving the $\mathrm{O} 1$ oxygen atom of $\mathrm{PO}_{3}{ }^{-}$and the $\mathrm{NZ}$ atom of Lys14 (red), the $\mathrm{O} 2$ oxygen atom of $\mathrm{PO}_{3}{ }^{-}$and $\mathrm{Mg}^{2+}$ (purple), the $\mathrm{O} 3$ oxygen atom of $\mathrm{PO}_{3}{ }^{-}$and the $\mathrm{NH} 2$ and $\mathrm{NE}$ atoms of the essential Arg116 (green and blue, respectively) during the whole simulation (Figure $8 \mathrm{C}$ ). It has been previously suggested that Arg116/Arg117 might also act by activating the $\mathrm{Y}^{-}$ phosphate group of ATP for catalysis and also trigger the release of the product from the active site [22]. These studies revealed that Arg116 might also act by activating and positioning the metaphosphate intermediate for subsequent nucleophilic attack by the $\mathrm{C} 3$ hydroxyl group in 1. Moreover, considering that the conversion of ATP to ADP is exothermic $(-7.3 \mathrm{kcal} / \mathrm{mol})$, one would expect that the rate-limiting step of the reaction catalysed by SK would be the nucleophilic attack by the C3 hydroxyl group to the metaphosphate intermediate to afford a tetrahedral transition state. Potential inhibitors that target the SK enzyme might be mimetics of this tetrahedral species.

A dissociative mechanism is supported by the findings: (1) the distance observed between the phosphorus atom of ATP $y$ phosphate and the $\mathrm{C} 3$ hydroxyl atom of $\mathbf{1}$ during 32 ns of simulation of both SK/ATP/1 Michaelis complexes is over $5 \AA$ during most of the simulation. Therefore, both substrates seem to be quite far away to form a pentavalent phosphorane intermediate in which the two substrates are linked through a 
phosphorus atom with distances between $\mathrm{O}$ and $\mathrm{P}$ atoms close to a single O-P bond $(\sim 1.6 \AA)$; and (2) the results from our NMR studies showing that the enzyme seems to be able to recognize metaphosphoric acid to perform the stereospecific phosphorylation of the C3 hydroxyl group in 1, as occurs on using ATP as the phosphorus source and when a closed form of the active site is achieved either using ADP, AMPNP or AMPCP. Hybrid $Q M / M M$ calculations are required to gain further insights into the catalytic mechanism in atomic detail and this study is currently in progress in our laboratories.

\section{Conclusions}

The results reported here indicate that the reaction catalysed by SK would involve a dissociative phosphoryl-transfer mechanism via a metaphosphate intermediate. Commercially available metaphosphoric acid proved to be a good mimetic of the latter intermediate, the transformation of which by the enzyme can be easily followed by $1 \mathrm{D}{ }^{1} \mathrm{H}$ and ${ }^{31} \mathrm{P}$ NMR spectroscopy. These experiments require the presence of $A D P$ or a synthetic analogue of ADP, such as AMPNP or AMPCP in order to achieve a closed form of the LID with the guanidinium group of the essential arginine (Arg116/Arg117 in $H$. pylori and $M$. tuberculosis, respectively) in close contact with the substrates and products. Of the two synthetic analogues of ADP used in these studies, AMPNP proved to me more efficient than when using AMPCP. The results of the MD simulation studies suggested that AMPNP and ADP would provide a better disposition of shikimic acid in the active site for catalysis than AMPCP, which might account for their higher efficiency. The results of the simulation studies also suggest that the essential arginine would also be involved in the stabilization of the metaphosphate intermediate during the catalysis. We believe that the NMR studies reported here would be helpful for the future mechanism- and structure-based design of inhibitors of this attractive target for antibiotic drug discovery as well as for the ready and rapid evaluation of possible dissociative phosphoryl-transfer mechanisms of other kinase enzymes.
A

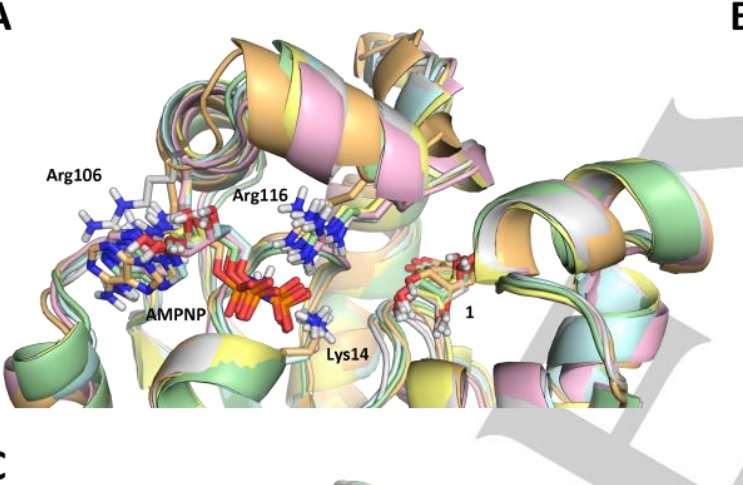

C

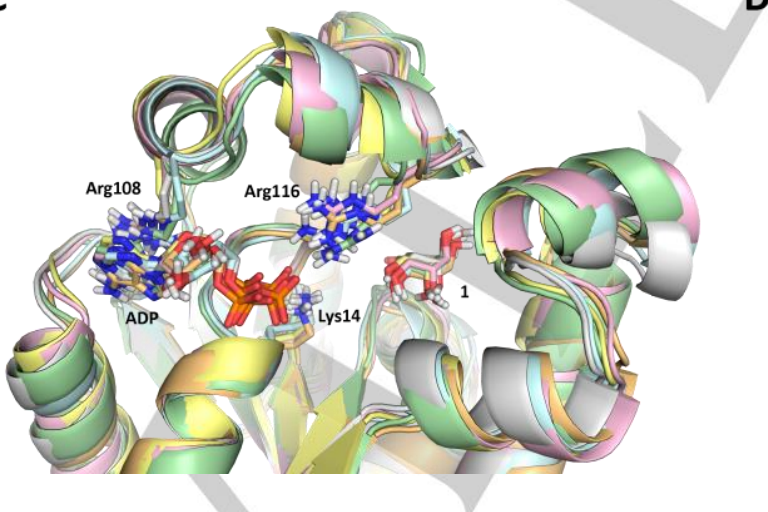

B

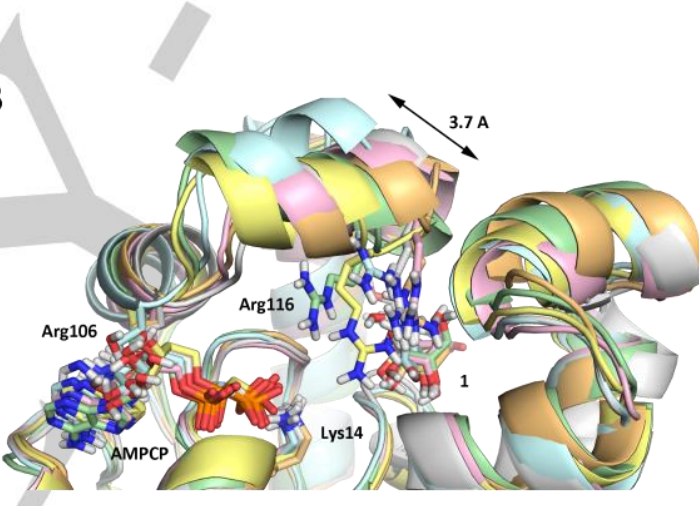

D

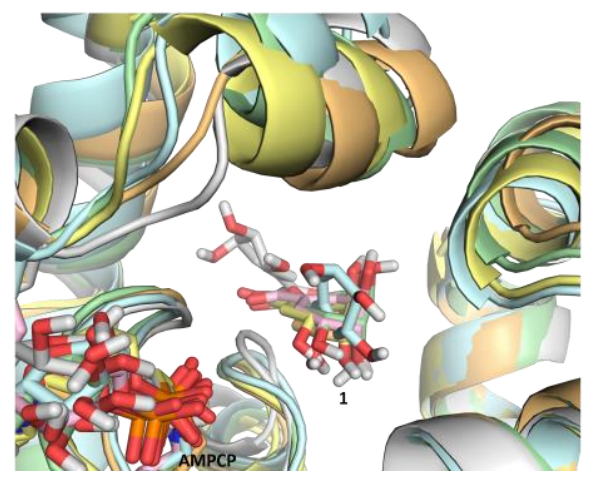

Figure 7. Comparison of several snapshots of the position of shikimic acid (1), ADP and the two ADP analogues in the Hp-SK/AMPNP/1 (A), Hp-SK/AMPCP/1 $(B, D) H p-S K / A D P / 1(C)$ complexes during $50 \mathrm{~ns}$ of MD simulations. Note how in the $H p$-SK/AMPNP/1 and Hp-SK/ADP/1 complexes the position of the essential arginine side chain and the substrate covering-loop remain stable during simulation. In contrast, for the $\mathrm{Hp}$-SK/AMPCP/1, a less stable closed arrangement of the active site is obtained. Only relevant side chain residues are shown and labelled. 
A

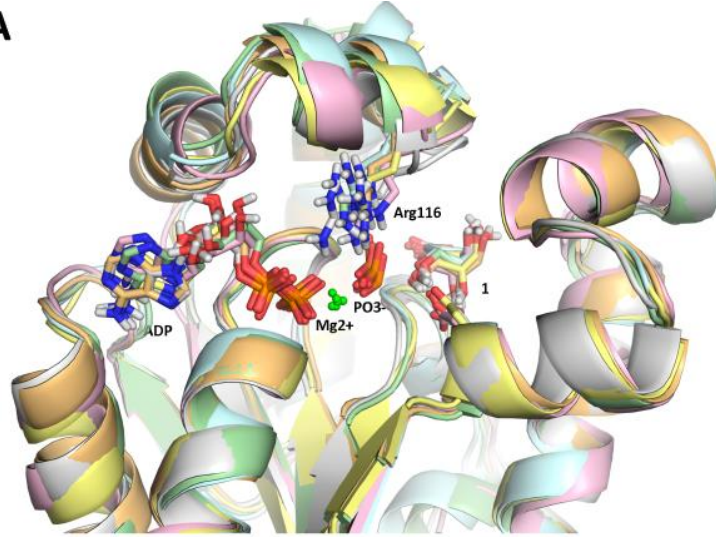

C



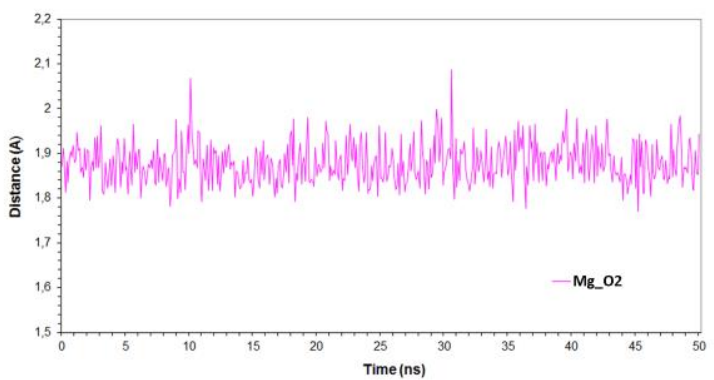

B
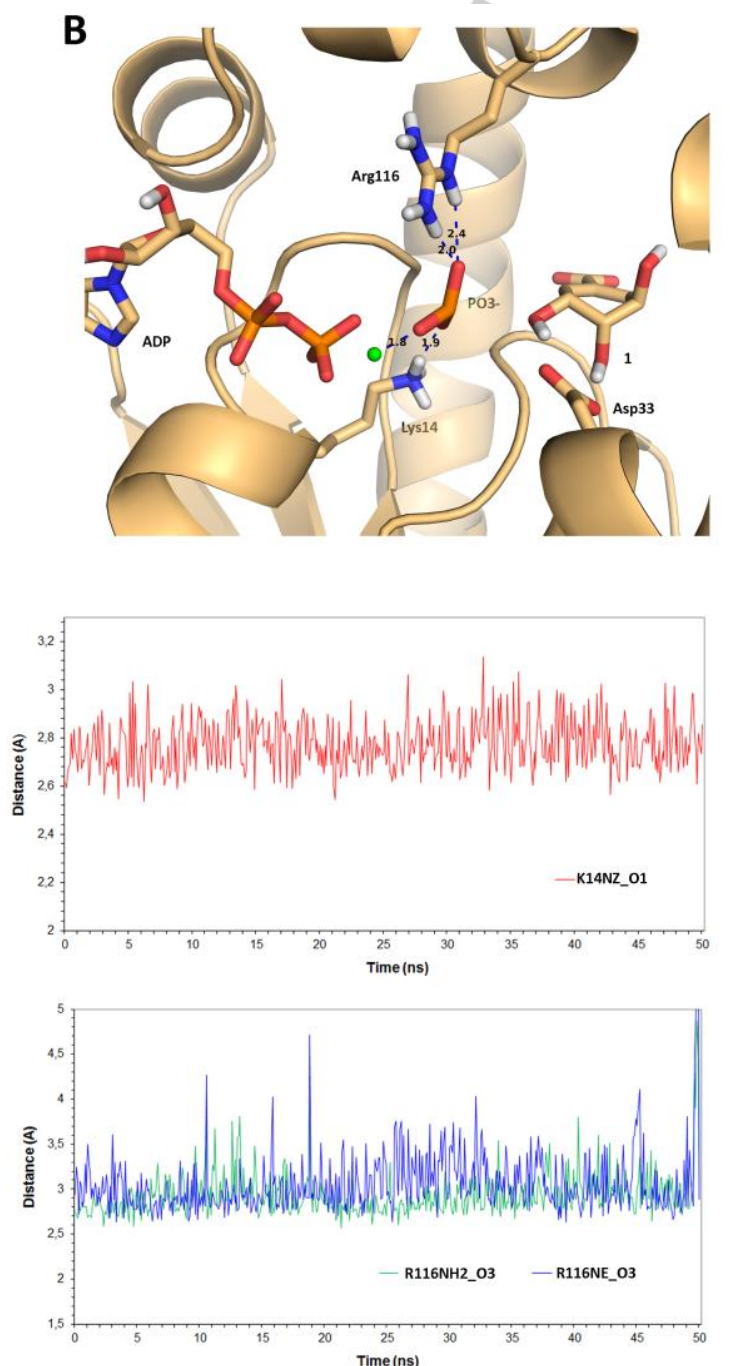

Figure 8. MD simulation studies of $\mathrm{Hp}-\mathrm{SK} / \mathrm{ADP} / \mathrm{PO}_{3} / \mathbf{1}$ complex. (A) Comparison of several snapshots of the position of $\mathrm{ADP}$, the metaphosphate intermediate and the substrate in the $\mathrm{Hp}-\mathrm{SK} / \mathrm{ADP} / \mathrm{PO}_{3} / \mathbf{1}$ complex during $50 \mathrm{~ns}$ of $\mathrm{MD}$ simulations. Note how the metaphosphate intermediate remains trapped between the ADP and the substrate during the simulation, mainly due to the strong electrostatic interaction with the guanidinium group of the essential Arg116. (B) Detailed view of the relevant binding interactions of the metaphosphate intermediate in the active site of $H p$-SK after 10 ns of MD simulation. (C) Variation of the distance between the $\mathrm{O} 1$ oxygen atom of $\mathrm{PO}_{3}^{-}$and the $\mathrm{NZ}$ atom of $\mathrm{Lys} 14$ (red), the $\mathrm{O} 2$ oxygen atom of $\mathrm{PO}_{3}^{-}$and $\mathrm{Mg}^{2+}$ (purple), the O3 oxygen atom of $\mathrm{PO}_{3}^{-}$and the $\mathrm{NH} 2$ and $\mathrm{NE}$ atoms of the essential Arg116 (green and blue, respectively) during $50 \mathrm{~ns}$ of MD simulation of the two $\mathrm{Hp}-\mathrm{SK} / \mathrm{ADP}^{\mathrm{P} O} \mathrm{O}_{3} / \mathbf{1} \mathrm{complexes}$. Relevant side-chain residues are shown and labelled.

\section{Experimental Section}

Helicobacter pylori SK cloning, expression and purification. The aroK gene, which encodes $\mathrm{Hp}$-SK, was PCR-amplified using genomic DNA from an isolated clinical strain, courtesy of the Guadalajara Hospital (Guadalajara, Spain) as template with the Expand High Fidelity PCR System (Roche). H. pylori strain was cultured in Columbia agar plates in microaerobic conditions (GasPak ${ }^{\mathrm{TM}}$ EZ CampyPouch ${ }^{\mathrm{TM}}$ System, Becton and Dickinson). The forward primer included a recognition site for the restriction Ndel enzyme (5'CGCATCCATATGCAGCATTTAGTTTTAATCG-3') and the reverse primer for the restriction enzyme BamH (5'CGGGATCCTTATGCGATGAATTGTAGCAC-3'). The PCR-amplified fragment, corresponding to aroK gene, was digested with $\mathrm{Ndel}$ and $\mathrm{BamH}$ and ligated to the expression vector pET3a previously digested with the same restriction enzymes. Comparison of the amino acid sequence in Hp-SK enzymes from AROK_HELPY, P56073 (strain ATCC 700392/26695) with clinically isolated strain from Guadalajara Hospital (Spain) revealed that the latter strain has three changes, specifically V75I, M99I and T123A (Figure S7). A similar comparison with AROK_HELPJ, Q9ZMS3 (strain J99 / ATCC 700824) showed two changes, specifically M99l and T123A.

The nucleotide sequence encoding the Hp-SK enzyme was subcloned into the Escherichia coli expression plasmid pET3a via 5/Nde1 and 3'BamH1 sites. The resulting plasmid was designated pMUT319. E. coli 
strain BL21-Al was transformed with pMUT319 and transformants were selected at $37^{\circ} \mathrm{C}$ on Luria Broth (LB) agar supplemented with $100 \mathrm{mg}$ $\mathrm{mL}^{-1}$ ampicillin. Transformed cells were grown in drug supplemented LB at $25{ }^{\circ} \mathrm{C}$ to an attenuance of 0.8 at $550 \mathrm{~nm}$, at which time the temperature was reduced to $15{ }^{\circ} \mathrm{C}$. The culture medium was then made $0.2 \%(\mathrm{w} / \mathrm{v})$ with arabinose and the incubation continued at $15{ }^{\circ} \mathrm{C}$ for a further $15 \mathrm{~h}$. Cells were harvested by centrifugation $\left(4^{\circ} \mathrm{C}, 10,000 \times \mathrm{g}, 10\right.$ min.) and stored at $-20{ }^{\circ} \mathrm{C}$ until needed. $50 \mathrm{~g}$ of cell paste was sonicated at $4{ }^{\circ} \mathrm{C}$ in $50 \mathrm{mM}$ potassium phosphate buffer $\mathrm{pH} 7.2,150 \mathrm{mM} \mathrm{NaCl}, 1$ $\mathrm{mM}$ DTT, $1 \mathrm{mM}$ benzamidine (buffer 1). Insoluble material was removed at $4{ }^{\circ} \mathrm{C}$ by centrifugation at $21,860 \mathrm{xg}$ for $1 \mathrm{~h}$. The clarified supernatant was then applied to a $Q$ sepharose column $(5 \times 15 \mathrm{~cm})$ equilibrated in 50 $\mathrm{mM}$ potassium phosphate buffer $\mathrm{pH}$ 7.2, $150 \mathrm{mM} \mathrm{NaCl}, 1 \mathrm{mM}$ DTT (buffer 2). The column flow through and a $1 \mathrm{~L}$ wash of buffer 2 were combined and made $35 \%$ saturated with ammonium sulfate. Precipitated material was removed at $4{ }^{\circ} \mathrm{C}$ by centrifugation at $13,690 \times \mathrm{x}$ for $1 \mathrm{~h}$. The supernatant was made $55 \%$ saturated with ammonium sulfate and the precipitated material recovered by centrifugation at $13,690 \times \mathrm{g}$ for $1 \mathrm{~h}$. The pellet was recovered, dissolved in $170 \mathrm{~mL}$ of $50 \mathrm{mM}$ potassium phosphate buffer $\mathrm{pH} 7.2,150 \mathrm{mM} \mathrm{NaCl}, 1 \mathrm{mM}$ DTT, $1.0 \mathrm{M}$ ammonium sulfate (buffer 3 ) and loaded on to a phenyl Sepharose column $(5 \times 15 \mathrm{~cm})$ equilibrated in buffer 3 . Following a $1.0 \mathrm{~L}$ wash with buffer 3 , the column was eluted with a $1 \mathrm{~L}$ ammonium sulfate gradient $(1.0 \mathrm{M}$ to $0.0 \mathrm{M}$ in buffer 2) collecting $1 \mathrm{~mL}$ fractions. At the end of the gradient the column was washed with a further $500 \mathrm{~mL}$ of buffer 3 collecting $10 \mathrm{~mL}$ fractions. $H p$-SK containing fractions were identified by SDS-PAGE $(12 \% \mathrm{gel})$ and pooled appropriately. Hp-SK protein was then dialysed against $3 \times 5 \mathrm{~L}$ changes of $25 \mathrm{mM}$ potassium phosphate buffer $\mathrm{pH} 6.6,150 \mathrm{mM} \mathrm{NaCl}, 1$ mM DTT (buffer 4) and loaded onto a hydroxyapatite column $(5 \times 7.5 \mathrm{~cm})$ equilibrated in buffer 4 . Following a $500 \mathrm{~mL}$ wash with buffer 4 , the column was then eluted with a gradient of potassium phosphate buffer pH $6.6(1 \mathrm{~L}, 25$ to $400 \mathrm{mM}$ ) containing $150 \mathrm{mM} \mathrm{NaCl}$ and $1 \mathrm{mM}$ DTT collecting $10 \mathrm{~mL}$ fractions. Hp-SK containing fractions were identified by SDS-PAGE (12\% gel) and pooled appropriately. The pooled protein (100 $\mathrm{mL}$ ) was dialysed against $5 \mathrm{~L}$ buffer 2 yielding approximately $820 \mathrm{mg}$ of $\mathrm{Hp}$-SK at greater than $95 \%$ purity.

Shikimate kinase assay. A concentrated solution of $H p-S K(7.4 \mathrm{mg} \mathrm{mL}$ ${ }^{1}$ ) in potassium phosphate buffer (50 mM, pH 7.2), DTT (1 mM) and $\mathrm{NaCl}$ $(150 \mathrm{mM})$, which was stored at at $-80^{\circ} \mathrm{C}$, was used. Shikimate kinase from M. tuberculosis (Mt-SK) was purified as described previously [24] and the concentrated solution $\left(1.5 \mathrm{mg} \mathrm{mL}^{-1}\right)$ was stored in potassium phosphate buffer $(50 \mathrm{mM}, \mathrm{pH} 7.2)$, DTT $(1 \mathrm{mM})$ and $\mathrm{NaCl}(150 \mathrm{mM})$ at $-80^{\circ} \mathrm{C}$. When required for assays aliquots of the enzyme stocks were diluted into buffer and stored on ice. Enzyme activity was measured by monitoring the decrease in absorbance at $340 \mathrm{~nm}$ in the UV spectrum due to the absorbance of $\operatorname{NADH}\left(\varepsilon / \mathrm{M}^{-1} \mathrm{~cm}^{-1} 6200\right)$ in a coupled assay format wherein ADP formed after the formation of shikimate-3-phosphate (2) was detected using pyruvate kinase (PK) and lactate dehydrogenase (LDH). Oxidation of NADH to NAD during PK-LDH activity was monitored at $340 \mathrm{~nm}$. Standard assay conditions for shikimate kinase were $100 \mathrm{mM}$ Tris. $\mathrm{HCl} \mathrm{pH} \mathrm{7.7,} 100 \mathrm{mM} \mathrm{NaCl}, 5 \mathrm{mM} \mathrm{MgCl} 2,2.5 \mathrm{mM}$ ATP, $1 \mathrm{mM}$ shikimic acid (1), $0.20 \mathrm{mM} \mathrm{NADH}, \sim 2.8$ units of PK-LDH and 0.03 unit of SK protein. One unit of enzyme is defined as the amount of enzyme required to convert $1 \mu \mathrm{mol}$ of substrate to product in $1 \mathrm{~min}$. Each assay was initiated by addition of shikimic acid (1). Solutions of ATP and NADH were calibrated by measuring the absorbance at $259 \mathrm{~nm}$ and $340 \mathrm{~nm}$ in the UV spectrum, respectively. Solutions of shikimic acid (1) were calibrated by equilibration with SK and measurement of the change in the UV absorbance at $340 \mathrm{~nm}$ due to the disappearance of NADH. The initial rates at fixed enzyme and substrate concentrations $\left(0.2-5 K_{\mathrm{m}}\right)$ were measured. Kinetic constants were evaluated using the GraFit 5 program (Erithacus Software Ltd.). The determined kinetic parameters for $\mathrm{Hp}$-SK and $M t$-SK were $K_{m}(\mathbf{1})=39 \pm 8 \mu \mathrm{M} ; k_{\text {cat }}=116 \pm 410^{-3} \mathrm{~s}^{-1}$ and $K_{m}(\mathbf{1})=$ $544 \pm 14 \mu \mathrm{M} ; k_{\mathrm{cat}}=295 \pm 8 \mathrm{~s}^{-1}$, respectively (Table S1).

Molecular Dynamics Simulations. Ligand preparation. Ligand geometries were minimized using a restricted Hartree-Fock (RHF) method and a $6-31 \mathrm{G}(\mathrm{d})$ basis set, as implemented in the ab initio program Gaussian 09 [28]. Ligands were manually docked into the active site. The resulting wavefunctions were used to calculate electrostatic potential-derived (ESP) charges employing the restrained electrostatic potential (RESP) [23] methodology, as implemented in the assisted model building with energy refinement (AMBER) [29] suite of programs. The missing bonded and non-bonded parameters were assigned, by analogy or through interpolation, from those already present in the AMBER database (GAFF) [30].

Generation and minimization of the SK Michaelis complexes. b) Mt-SK model: simulations were carried out using the enzyme coordinates found in the crystal structure of $M t$-SK in complex with ADP and shikimic acid (1) (PDB code 2IYQ [21]) and after manual replacement of ADP by ATP. b) Hp-SK model: These studies were carried out using the enzyme coordinates found in the crystal structure of $H p-S K / A D P / 2$ complex (PDB code 3MUF [20]) after manual replacement of both products by the substrates.

Crystallographic water molecules were maintained in both complexes except for those coordinated with the $\beta$-phosphate of ADP in PDB 2IYQ. For the two Michaelis complexes, the crystallographic water molecules coordinated with the $\mathrm{y}$-phosphate of ATP and $\mathrm{Mg}^{2+}$ in PDB 2IYW were also added. Protein $\mathrm{N}$ - and $\mathrm{C}$-terminal groups were modified as $\mathrm{N}$-acetyl and $\mathrm{N}$-methyl amide derivatives, respectively. Computation of the protonation state of titratable groups at $\mathrm{pH} 7.0$ were carried out using the $\mathrm{H}^{++}$Web server [31]. Addition of hydrogen and molecular mechanics parameters from the ff03 and GAFF force fields, respectively, were assigned to the protein and the ligands using the LEaP module of AMBER 12 [32]. ATP, ADP and $\mathrm{Mg}^{2+}$ parameters used with the AMBER force field were included [33-35]. Energy minimization using the implicit solvent GB model was then carried out in stages, starting with ligand (1000 steps, half of them steepest descent, the other half conjugate gradient), protein side chains (1000 steps, idem) and finally the entire complex (1000 steps, idem). A positional restraint force constant of 50 $\mathrm{kcal} \mathrm{mol}^{-1} \AA^{-2}$ was applied to those unminimized atoms in each step during all calculations. The complex was neutralized by addition of chloride ions and immersed in a truncated octahedron of $\sim 5300$ TIP3P water molecules [36-38].

Simulations. MD simulations were performed using the sander module [39] from the AMBER 12 suite of programs. Periodic boundary conditions were applied, and electrostatic interactions were treated using the smooth particle mesh Ewald method (PME) [40] with a grid spacing of 1 $\AA$. The cutoff distance for the nonbonded interactions was $9 \AA$. The SHAKE algorithm [41] was applied to all bonds containing hydrogen, using a tolerance of $10^{-5} \AA$ and an integration step of 2.0 fs. Minimization was carried out in three steps, starting with the octahedron water hydrogens, followed by solvent molecules and counterions, and finally the entire system. The minimized system was heated at $300 \mathrm{~K}$ (1 atm, $200 \mathrm{ps}$, a positional restraint force constant of $50 \mathrm{kcal} \mathrm{mol}^{-1} \AA^{-2}$ ). These initial harmonic restraints applied to all $\alpha$ carbons were gradually reduced from 5 to $1 \mathrm{~mol}^{-1} \AA^{-2}$ ( 6 steps, $100 \mathrm{ps}$ each), and the resulting systems were allowed to equilibrate further (100 ps). Unrestrained MD simulations were carried out for $32 \mathrm{~ns}$. System coordinates were collected every 10 ps for further analysis. Figures depicting structures were prepared using PYMOL [42]. 
NMR Experiments. All NMR experiments were performed on a Varian Inova 500 spectrometer at $500 \mathrm{MHz}\left({ }^{1} \mathrm{H}\right)$ or $202 \mathrm{MHz}\left({ }^{31} \mathrm{P}\right)$ and $298 \mathrm{~K}$ using shikimic acid (1) $(6.4 \mathrm{mM})$, ADP sodium salt $(4.5 \mathrm{mM}), \mathrm{KCl}(100$ $\mathrm{mM})$ and $\mathrm{MgCl}_{2}(5 \mathrm{mM})$ in Tris- $d_{11} . \mathrm{DCl}(100 \mathrm{mM}, \mathrm{pD} 7.7)$ and a catalytic amount of $\mathrm{Hp}$-SK (10 units) or Mt-SK (3 units). The reaction was initiated by the addition of a solution of metaphosphoric acid $(18 \mathrm{mM})$ to a solution of $1, \mathrm{ADP}, \mathrm{KCl}, \mathrm{MgCl}_{2}$ in deuterated buffer. The stock samples of 1 (50 $\mathrm{mM}), \mathrm{ADP}(50 \mathrm{mM})$ and metaphosphoric acid $(1 \mathrm{M})$ were prepared in deuterated buffer. The total volume of each NMR sample was $550 \mu \mathrm{L}$. Solvent suppression of the residual HDO peak was achieved by continuous low power presaturation pulse during the relaxation delay. NMR spectra were recorded prior and after the addition of metaphosphoric acid over $96 \mathrm{~h}$ period, unless is indicated.

The NMR experiments carried with adenosine- $5^{\prime}-[(\alpha, \beta)$ imido]diphosphate sodium salt (AMPNP) and adenosine- $5^{\prime}-[(\alpha, \beta)$ methyleno]diphosphate sodium salt (AMPCP), which were purchase from Jena Bioscience, were performed as those with ADP (see above). It was employed shikimic acid (1) (3.2 mM), AMPNP (1.8 mM), KCl (100 mM) and $\mathrm{MgCl}_{2}(5 \mathrm{mM})$ in Tris- $d_{11} . \mathrm{DCl}(100 \mathrm{mM}$, pD 7.7), metaphosphoric acid $(18 \mathrm{mM})$ and a catalytic amount of $\mathrm{Hp}$-SK (10 units). For those experiments carried out with AMPCP $(4.5 \mathrm{mM})$, a higher concentration of metaphosphoric acid ( $36 \mathrm{mM}$ ) was employed. After $18 \mathrm{~h}$ incubation, more metaphosphoric acid was added ( $10 \mu \mathrm{L}$ of $1 \mathrm{M}$ stock) to achieve a total concentration of $54 \mathrm{mM}$. For those control experiments carried out in the absence of ADP or the enzyme, the corresponding amount was replaced by deuterated buffer.

The NMR monitoring of the enzymatic conversion of shikimic acid (1) and ATP to provide shikimate 3-phosphate (2) and ADP was carried out using ATP magnesium salt (4.5 mM), shikimic acid (1) $(6.4 \mathrm{mM}), \mathrm{KCl}(100 \mathrm{mM})$ and $\mathrm{MgCl}_{2}(5 \mathrm{mM})$ in Tris- $d_{11} . \mathrm{DCl}(100 \mathrm{mM}$ pD 7.7). NMR spectra were recorded prior and after the addition of $\mathbf{1}$ to detect possible changes in the ATP. The reaction was then initiated with the addition of a catalytic amount of Mt-SK (0.3 units). NMR spectra were immediately recorded after the addition of the enzyme and over $18 \mathrm{~h}$ period.

\section{Acknowledgements}

Financial support from the Spanish Ministry of Economy and Competiveness (SAF2013-42899-R), Xunta de Galicia (GRC2013-041) and the European Regional Development Fund (ERDF) is gratefully acknowledged. VP and EL thank the Spanish Ministry of Economy and Competiveness and Xunta de Galicia for their respective FPI and postdoctoral fellowships. JAV and $A B$ thank the Sara Borrell Programme (CD13/00373) and the ISCIII General Subdirection of Assesment and Promotion of the Research (PI14/00059), respectively, for financial support. We are grateful to Dr. Trinidad Parra Cid from Guadalajara Hospital (Guadalajara, Spain) for kindly providing the isolated clinical strain of Helicobacter pylori and to the Centro de Supercomputación de Galicia (CESGA) for use of the Finis Terrae computer.

Keywords: Enzyme mechanism • Molecular Dynamics Simulations $\cdot$ Dissociative $\cdot$ Kinases

[1] J. R. Knowles, Annu. Rev. Biochem. 1980, 49, 877-919.

[2] F. H. Westheimer, Science 1987, 235, 1173-1178.
[3] W. W. Cleland, A. C. Hengge, Chem. Rev. 2006, 106, 3252-3278.

[4] J. K. Lassila, J. G. Zalatan, D. Herschlag, Annu. Rev. Biochem. 2011 80, 669-702.

[5] K. D. Allen, D. Dunaway-Mariano, Trends in Biochem. Sci. 2004, 29, 495-503.

[6] A. C. Hengge, Adv. Phys. Org. Chem. 2005, 40, 49-108.

[7] N. Strater, W. N. Lipscomb, T. Klabunde, B. Krebs, Angew. Chem. Int. Ed. Engl. 1996, 35, 2024-2055.

[8] S. Liu, Z. Lu, Y. Jia, D. Dunaway-Mariano, O. Herzberg, Biochemistry 2002, 41, 10270-10276.

[9] K. Parang, J. H. Till, A. J. Ablooglu, R. A. Kohanski, S. R. Hubbard, P. A. Cole, Nature Struct. Biol. 2001, 8, 37-41.

[10] S. D. Lahiri, G. Zhang, D. Dunaway-Mariano, K. D. Allen, Science 2003, 299, 2067-2071.

[11] S. T. Mundle, J. C. Delaney, J. M. Essigmann, P. R. Strauss, Biochemistry 2009, 48, 19.26 .

[12] M. C. Hutter, V. Helms, Protein Science 2000, 9, 2225-2231.

[13] S. Loverix, A. Winqvist, R. Stromberg, J. Steyaert, Chem. Biol. 2000, 7 651-658.

[14] A. M. Sudom, L. Prasad, H. Goldie, L. T. J. Delbaere, J. Mol. Biol. 2001, 314, 83-92.

[15] Y-W Xu, S. Morera, J. Janin, J. Cherfils, Proc. Natl. Acad. Sci. USA, 1997, 94, 3579-3583.

[16] M. Valiev, R. Kawai, J. A. Adams, J. H. Weare, J. Am. Chem. Soc. 2003, 125, 9926-9927

[17] G. K. Smith, Z. Ke, H. Guo, J. Phys. Chem. 2011, 115, 13713-13722.

[18] B. Elsässer, S. Dohmeier-Fischer, G. Fels. J. Mol. Model. 18, 3169 3179.

[19] For other 31P NMR studies on kinases see: a) M. Cohn, Curr. Top. Cell. Reg. 1984, 24, 1-13. b) N. M. Doliba, A. M. Babsky, N. M. Doliba, S. L. Wehrli, M. D. Osbakken, Cell. Biochem. Funct. 2015, 33, 67-72. c) C. Gabellieri, M. Beloueche-Babari, Y. Jamin, G. S. Payne, M. O. Leach, T. R. Eykyn, NMR Biomed. 2009, 22, 456-461. d) G. Fayat, S. Blanquet, B. D. N. Rao, M. Cohn, J. Biol. Chem. 1980, 255, 8164-8169. e) B. D. Rao, D. H. Buttlaire, M. Cohn, J. Biol. Chem. 1976, 251, 6981-6986. f A. Lecroisey, I. Lascu, A. Bominaar, M. Veron, M. Delepierre, Biochemistry 1995, 34, 12445-12450. g) M. Shimane, Y. Sugai, R Kainuma, M. Natsume, H. Kawaide, Bios. Biotech. Biochem. 2012, 76, 1558-1560. h) H.-W. Kim, B. Yeh, J.-W. Choi, Y.-S. Jeong, J.-H. Sohn, J.-H. Kim, Bull. Korean Chem. Soc. 2012, 33, 2419-2422.

[20] W. C. Cheng, Y. F. Chen, H. J. Wang, K. C. Hsu, S. C. Lin, T. J. Chen T. J., Yang, J. M., W. C. Wang, Plos One 2012, 7, e33481.

[21] M. D. Hartmann, G. P. Bourenkov, A. Oberschall, N. Strizhov, H. D. Bartunik, J. Mol. Biol. 2006, 364, 411-423.

[22] B. Blanco, V. Prado, E. Lence, J. M. Otero, C. García-Doval, M. J. van Raaij, A. L. Llamas-Saiz, H. Lamb, A. R. Hawkins, C. González-Bello, J. Am. Chem. Soc. 2013, 135, 12366-12376.

[23] a) W. D. Cornell, P. Cieplak, C. I. Bayly, I. R. Gould, K. M. Merz, D. M. Ferguson, D. C. Spellmeyer, T. Fox, J. W. Caldwell, P. A. Kollman, J. Am. Chem. Soc. 1995, 117, 5179-5197. b) http://q4mdforcedfieldtools.org/RED/resp/

[24] T. Krell, J. Maclean, D. J. Boam, A. Cooper, M. Resmini, K. Brocklehurst, S. M. Kelly, N. C. Price, A. J. Lapthorn, J. R. Coggins, Protein Science 2001, 10, 1137-1149.

[25] Y. Gu, L. Reshentnikova, Y. Li, Y. Wu, H. Yan, S. Singh, X. Ji, J. Mol. Biol. 2002, 319, 779-789.

[26] B. Dhaliwal, C. E. Nichols, J. Ren, M. Lockyer, I. Charles, A. R Hawkins, D. K. Stammers, FEBS Lett. 2004, 574, 49-54.

[27] B. R. Miller III, T. D. McGee Jr., J. M. Swails, N. Homeyer, H. Gohlke, and A. E. Roitberg, J. Chem. Theory Comput. 2012, 8, 3314-3321.

[28] M. J. Frisch, G. W. Trucks, H. B. Schlegel, G. E. Scuseria, M. A. Robb, J. R. Cheeseman, G. Scalmani, V. Barone, B. Mennucci, G. A. Petersson, H. Nakatsuji, M. Caricato, X. Li, H. P. Hratchian, A. F. Izmaylov, J. Bloino, G. Zheng, J. L. Sonnenberg, M. Hada, M. Ehara, K. Toyota, R. Fukuda, J. Hasegawa, M. Ishida, T. Nakajima, Y. Honda, O. 
Kitao, H. Nakai, T. Vreven, J. A. Montgomery, Jr., J. E. Peralta, F. Ogliaro, M. Bearpark, J. J. Heyd, E. Brothers, K. N. Kudin, V. N. Staroverov, R. Kobayashi, J. Normand, K. Raghavachari, A. Rendell, J. C. Burant, S. S. lyengar, J. Tomasi, M. Cossi, N. Rega, J. M. Millam, M. Klene, J. E. Knox, J. B. Cross, V. Bakken, C. Adamo, J. Jaramillo, R. Gomperts, R. E. Stratmann, O. Yazyev, A. J. Austin, R. Cammi, C. Pomelli, J. W. Ochterski, R. L. Martin, K. Morokuma, V. G. Zakrzewski, G. A. Voth, P. Salvador, J. J. Dannenberg, S. Dapprich, A. D. Daniels, Ö. Farkas, J. B. Foresman, J. V. Ortiz, J. Cioslowski, D. J. Fox, Gaussian 09, revision A.2, Gaussian, Inc., Wallingford CT, 2009.

[29] D. A. Case, T. E. Cheatham, T. Darden, H. Gohlke, R. Luo, K. M. Merz, O. Onufriev, C. Simmerling, B. Wang, R. J. Woods, J. Comput. Chem. 2005, 6, 1668-1688.

[30] a) J. Wang, W. Wang, P. A. Kollman, D. A. Case, J. Mol. Graphics Modell. 2006, 25, 247-260. b) http://q4mdforcedfieldtools.org/RED/resp/].

[31] a) J. C. Gordon, J. B. Myers, T. Folta, V. Shoja, L. S. Heath, A. Onufriev, Nucleic Acids Res. 2005, 33 (Web Server issue):W368-W371. b) http://biophysics.cs.vt.edu/H++

[32] Case, D. A., Darden, T. A., Cheatham III, T. E., Simmerling, C. L., Wang, J., Duke, R. E., Luo, R., Walker, R. C., Zhang, W., Merz, K. M., Roberts, B., Hayik, S., Roitberg, A., Seabra, G., Swails, J., Goetz, A W., Kolossváry, I., Wong, K. F., Paesani, F., Vanicek, J., Wolf, R. M., Liu, J., Wu, X., Brozell, S. R., Steinbrecher, T., Gohlke, H., Cai, Q., Ye, X., Wang, J., Hsieh, M.-J., Cui, G., Roe, D. R., Mathews, D. H., Seetin,
M. G., Salomon-Ferrer, R., Sagui, C., Babin, V., Luchko, T., Gusarov, S., Kovalenko, A., Kollman, P. A. AMBER 12, University of California San Francisco, 2012.

[33] O. Allnér, L. Nilsson, A. Villa, J. Chem. Theory Comput. 2012, 8, 14931502.

[34] $\mathrm{Mg}^{2+}$ parameters used with the AMBER force field were downloaded from http://www.pharmacy.manchester.ac.uk/bryce/amber/.

[35] K. L. Meagher, L. T. Redman, H. A. Carlson, J. Comput. Chem. 2003 24, 1016-1025.

[36] D. A. Case, T. E. Cheatham, T. Darden, H. Gohlke, R. Luo, K. M. Merz, O. Onufriev, C. Simmerling, B. Wang, R. J. Woods, J. Comput. Chem. 2005, 26, 1668-1688.

[37] J. Aqvist, J. Phys. Chem. 1990, 94, 8021-8024

[38] W. L. Jorgensen, J. Chandrasekhar, J. D. Madura, J. Chem. Phys. 1983, 79, 926-935.

[39] S. Le Grand, A. W. Goetz, R. C. Walker, Comp. Phys. Comm. 2013, 184, 374-380.

[40] R. Salomon-Ferrer, A. W. Goetz, D. Poole, S. Le Grand, R. C. Walker, J. Chem. Theory Comput. 2013, 9, 3878-3888.

[41] J.-P. Ryckaert, G. Ciccotti, H. J. C. Berendsen, J. Comput. Phys. 1977 23, 327-341.

[42] http://www.pymol.org 


\section{Entry for the Table of Contents}

\section{FULL PAPER}

NMR approach to study the possible dissociative phosphoryl-transfer mechanism of shikimate kinase is reported. Metaphosphoric acid proved to be a good mimetic of the reaction intermediate. A closed conformation of the active site, which is required for catalysis, was achieved by using ADP or synthetic analogues of ADP (AMPNP, AMPCP).

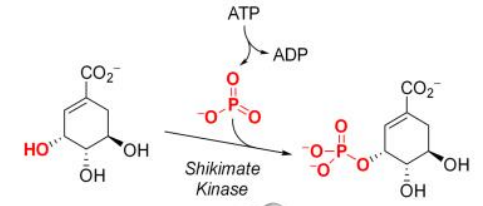

Verónica Prado, Emilio Lence, Juan A. Vallejo, Alejandro Beceiro, Paul

Thompson, Alastair R. Hawkins and Concepción González-Bello*

Page No. - Page No.

Study of the Phosphoryl-Transfer Mechanism of Shikimate Kinase by NMR Spectroscopy 